\title{
PV-Batarya Hibrit Sistemi İçeren Elektrikli Araç Otoparkının Şarj Yönetimi
}

\author{
Alper Çiçek $^{1 *}$, Ozan Erdinç ${ }^{1}$ \\ ${ }^{1}$ Yıldız Teknik Üniversitesi, Elektrik Mühendisliği Bölümü, İstanbul, Türkiye
}

(İlk Geliş Tarihi 14 Şubat 2019 ve Kabul Tarihi 20 Mart 2019)

(DOI: 10.31590/ejosat.527350)

ATIF/REFERENCE: Çiçek, A. \& Erdinç, O. (2019). PV-Batarya Hibrit Sistemi İçeren Elektrikli Araç Otoparkının Şarj Yönetimi. Avrupa Bilim ve Teknoloji Dergisi, (15), 466-474.

\section{Öz}

Dünyada enerji tüketiminde taşımacılık sektörünün önemli bir payı vardır. Bu enerjinin büyük çoğunluğu karbon salınımına sebep olan petrol ve türevi yakıtlar kullanılarak elde edilmektedir. Dolayısıyla sera gazı emisyonlarına sebep olmayan ve temiz enerji olarak adlandırılan yenilenebilir enerji kaynaklarının kullanımına gereksinim vardır. Ayrıca yenilenebilir enerji kaynaklarının kullanımına olanak veren ve içten yanmalı motorlara bir alternatif sunan elektrikli araçlar çevresel problemlerin bir çözümü olarak düşünülebilir. Elektrikli araç sayısına bakıldığında son yıllarda önemli bir artış olmuştur. Çok sayıda elektrikli aracın şarj olacağı düşünüldüğünde bu durum pik yükün artması, transformatörlerin aşırı yüklenmesi ve sistem kayıplarının artması gibi elektrik şebekesi açısından bir çok probleme sebep olabilir. Bu nedenle güç sistemlerinde şarj talebiyle ilgili endişeleri ortadan kaldırmak için uygun şarj stratejisinin belirlenmesi bu problemlerin giderilmesine yardımcı olabilir. Elektrikli araç sahipleri araçlarını şarj etmek için genellikle elektrikli araç otoparklarını tercih etmektedirler. Elektrikli araç otoparkları, elektrikli araç sahiplerine ekonomik şarj olanağı tanıması açısından avantajlı olarak düşünülebilir. Çünkü elektrikli araç otoparkına entegre edilen PV (Fotovoltaik sistem) - batarya hibrit sistemi elektrikli araç sahiplerine şarj maliyetlerini düşürmek için iyi bir firsat sunmaktadır. Ayrıca elektrikli araç otoparkları elektrik piyasasında yer alabilirler. Bu çalışmada PV-batarya hibrit sistem içeren bir otoparkta elektrikli araçların ekonomik açıdan en iyi şekilde şarj edilmesi için bir karışık tamsayılı doğrusal programlama modeli oluşturulmuştur. Yapılan çalışmada elektrikli araç otoparkı dinamik elektrik fiyatları ile enerji satın almaktadır. PV sistem araçlara gölge yapacak konumda düşünülmüştür. Batarya enerji depolama sistemi PV sistemde üretilen fazla enerjinin ve şebeke elektrik fiyatlarının düşük olduğu periyotlarda şebekeden satın alınan enerjinin depo edilmesi amacıyla modele dahil edilmiştir. Bataryadaki enerji, PV üretiminin olmadığı ya da şebeke elektrik fiyatının pahalı olduğu periyotlarda sisteme enjekte edilmektedir. Önerilen modelin doğruluğunu kanıtlamak için çeşitli durum çalışmaları yapılmıştır. Çalışma sonuçlarına göre PV-batarya hibrit sisteminin toplam elektrik maliyetini düşürdüğü görülmüştür. Dikkat çekici bir sonuç da PV üretiminin gerçekleştiği bazı periyotlarda şebekeden hiç güç çekilmemesidir. Genel olarak PV sistemin toplam elektrik maliyetini azaltma konusunda önemli bir katkısının olduğu sonucuna varılabilirken, batarya enerji depolama sisteminin elektrik maliyetinin düşürülmesi konusunda çok etkili olmadığı ifade edilebilir.

\section{Charge Management of Electric Vehicle Parking Lot With PV-Battery Hybrid System}

\begin{abstract}
The transportation sector has an important share in energy consumption in the world. The majority of this energy is obtained by using petroleum and derivative fuels that cause carbon emissions. Therefore, there is a need for the use of renewable energy sources which are called clean energy and don't cause greenhouse gas emissions. Furthermore, electric vehicles which allow the use of renewable
\end{abstract}

${ }^{1}$ Sorumlu Yazar: Yıldız Teknik Üniversitesi, Elektrik Mühendisliği Bölümü, İstanbul, Türkiye, alper_cicek92@hotmail.com 
Avrupa Bilim ve Teknoloji Dergisi

energy sources and provide an alternative to internal combustion engines, can be considered as a solution to environmental problems. There has been a significant increase in recent years in terms of the number of electric vehicles. Considering the fact that a large number of electric vehicles will be charged, this can cause many problems in terms of the power system such as peak load, overloading of transformers and increasing systems losses. Therefore, identifying the appropriate charging strategy to eliminate concerns about charging in the power system can help to address these problems. The electric vehicle owners generally prefer electric vehicle parking lots to charge their vehicles. The electric vehicle parking lots can be considered as an advantage in terms of providing economical charging to the electric vehicle owners. Because the PV-battery hybrid system integrated into the parking lot offers a good opportunity for the electric vehicle owners to reduce charging costs. The parking lots can be included in the electricity market. In this study, a mixed integer linear programming model was created for the economical charging of electrc vehicles in a parking lot with PV-battery hybrid system. The parking lot buys energy with dynamic electricity prices in the study. The PV system is designed to shade the vehicles. The battery is included in the model in order to store the energy of the excess energy produced in the PV system and purchased from the power system in periods when the electricity prices are low. The energy in the battery is injected into the system during periods when there is no PV production or electricity price are expensive. Several case studies have been conducted to prove the accuracy of the proposed model. According to the results of the study, it was seen that the PV-battery hybrid system reduced the total electricity cost. A remarkable result is that no power is drawn from the power system at certain periods when PV production takes place. In general, it can be concluded that the PV system has a significant contribution to reducing the total electricity cost, while the battery is not very effective in reducing the electricity cost.

Keywords: Electric vehicle, electric vehicle parking lot, PV-battery hybrid system, charge strategy.

\section{Adlar dizini}

\section{A. Kümeler}

Elektrikli araçlar kümesi

Gün periyodu [dakika]

\section{B. Parametreler}

\begin{tabular}{|c|c|}
\hline$F^{E S S}$ & $\begin{array}{l}\text { atarya enerji depolama sisteminin } \\
\text { erimliliği }\end{array}$ \\
\hline & elektrikli aracının şarj verimliliği \\
\hline$S$ & $\begin{array}{l}\text { atarya enerji depolama sisteminin deşarj } \\
\text { erimliliği }\end{array}$ \\
\hline$F$ & $n$ elektrikli aracının deşarj verimliliği \\
\hline$R^{E S S}$ & $\begin{array}{l}\text { Batarya enerji depolama sisteminin şarj gücü } \\
{[\mathrm{kW}]}\end{array}$ \\
\hline$R_{n}^{E}$ & $n$ elektrikli aracının şarj gücü $[\mathrm{kW}]$ \\
\hline$R^{E S S}$ & $\begin{array}{l}\text { atarya enerji depolama sisteminin deşarj gücü } \\
\text { W] }\end{array}$ \\
\hline$R_{m}^{E V}$ & $m$ elektrikli aracının deşarj gücü $[\mathrm{kW}]$ \\
\hline$P_{t}^{P V}$ & PV sistemde üretilen güç [kW] \\
\hline$s$, ini & $\begin{array}{l}\text { Batarya enerji depolama } \\
\text { başlangıçtaki enerji durumu }[\mathrm{kWh}]\end{array}$ \\
\hline$S S, \max$ & $\begin{array}{l}\text { ya enerji depolama sisteminin maksimum } \\
\text { düzeyi }[\mathrm{kWh}]\end{array}$ \\
\hline$S S, \min$ & $\begin{array}{l}\text { Batarya enerji depolama sisteminin minimum } \\
\text { enerji düzeyi }[\mathrm{kWh}]\end{array}$ \\
\hline$o E_{m}^{E V, i n i}$ & $\begin{array}{l}m \text { elektrikli aracının başlangıçtaki enerji } \\
\text { durumu }[\mathrm{kWh}]\end{array}$ \\
\hline$F$ & $\begin{array}{l}m \text { elektrikli aracının maksimum enerji düzeyi } \\
{[\mathrm{kWh}]}\end{array}$ \\
\hline$D$ & $\begin{array}{l}m \text { elektrikli aracının minimum enerji düzeyi } \\
{[\mathrm{kWh}]}\end{array}$ \\
\hline & $\begin{array}{l}m \text { elektrikli aracının elektrikli araç otoparkın } \\
\text { geliş zamanı }\end{array}$ \\
\hline & $\begin{array}{l}m \text { elektrikli aracının elektrikli } \\
\text { otoparkından ayrılma zamanı }\end{array}$ \\
\hline
\end{tabular}




\section{Değişkenler}

$\begin{array}{ll}P_{t}^{E S S, c h} & \begin{array}{l}\text { Batarya enerji depolama sisteminin } t \text { anındaki } \\ \text { şarj gücü [kW] }\end{array} \\ P_{m, t}^{E S S, \text { dis }} & \begin{array}{l}\text { Batarya enerji depolama sisteminin } t \text { anındaki } \\ \text { deşarj gücü [kW] }\end{array} \\ P_{m, t}^{E V, c h} & m \text { elektrikli aracının } t \text { anındaki şarj gücü [kW] } \\ P_{t}^{g r i d} & t \text { anında şebekeden çekilen güç [kW] } \\ S o E_{t}^{E S S} & t \text { anında batarya enerji depolama sisteminin enerji } \\ & \text { durumu [kWh] } \\ S o E_{m, t}^{E V} & t \text { anında } m \text { elektrikli aracının bataryasının enerji } \\ & \begin{array}{l}\text { durumu [kWh] } \\ \text { Batarya enerji depolama sistemi şarj ve deşarji }\end{array} \\ u^{E S S} & \text { için ikili karar değişkeni }\end{array}$

\section{Giriş}

\subsection{Motivasyon ve Geçmiş Çalış̧malar}

Dünyadaki toplam enerji tüketiminin \%27'sini ve sera gazı emisyonunun \%33'ünü taşımacılık sektörü oluşturmaktadır (Tie ve ark., 2012). Taşımacılık sektöründe tüketilen enerjinin çoğunluğu çevre kirliliğine ve sera gazı emisyonlarına sebep olan fosil yakıtlar kullanılarak temin edilmektedir. Fosil yakıtların azaltılması ihtiyacı elektrikli araçları içten yanmalı motorlara alternatif bir duruma getirmiştir (Jozi ve ark., 2017).

Elektrikli araçlar temiz ve verimli bir enerji olarak adlandırılan yenilenebilir enerji kaynaklarının kullanımına olanak tanımaktadır. PV (Fotovoltaik) sisteme sahip otoparklarda güneş panelleri park halindeki elektrikli araçlara gölge sağlamakta ve şarj için elektrik üretimi gerçekleştirmektedir. Ayrıca PV sistem bir batarya ile entegre edilerek şarj maliyeti azaltılabilir. Enerji depolama sisteminde hem PV sistemde üretilen fazla enerji hem de elektrik fiyatının düşük olduğu periyotlarda şebekeden satın alınan enerji depo edilebilir (Nunes ve ark., 2016).

Açıklanan bir rapora göre, dünyada toplam elektrikli araç sayısı 2016'ya kıyasla \%50'den fazla artmış durumdadır ve 3 milyonu aşmıştır (International Energy Agency, 2018). Çok sayıda aracın katılımı ile elektrik şebekesinin işleyişinde ve kontrolünde değişiklikler meydana gelmiştir. Sonuç olarak elektrikli araçların şarj edilmesi ile ilgili ortaya çıkan yük dalgalanmalarının önlenmesi, pik yükün azaltılması ve şebeke verimliliğinin arttırılması ele alınması gereken önemli konulardandır. Elektrikli araçların şarj stratejisinin doğru belirlenmesinin elektrik şebekesinde yaşanabilecek problemlerin üzerinde doğrudan etkili olabileceği ifade edilebilir (P. Zhang ve ark., 2016).

\subsection{Literatür Taraması}

Son yıllarda elektrikli araçlar oldukça popüler bir konuma gelmiştir. Elektrikli araç sayısının artmasının sonucunda şebekede bu araçların şarjları konusunda yaşanabilecek problemlerin olması sebebi ile bu konuda yapılan çalışmaların sayısı giderek artmaktadır.

Neyestani ve ark. (2015) dağıtım sistemi operatörü ve elektrikli araç otopark sahibi arasındaki etkileşimde karar verme aşamasında yaşanabilecek çatışmaların denge noktasını belirlemek için bir model önermişlerdir. Amaç fonksiyonunu dağıtım sistemi operatörü ve elektrikli araç sahibi açısından kârı maksimize etmek olarak belirlemişlerdir. Shafie-Khah ve ark. (2016) elektrikli araç otoparklarının enerji ve rezerv piyasalarındaki optimum davranışı konusunu ele almışlardır. Ayrıca talep cevabı programlarının otoparkların işletimsel davranışlarına olan etkilerini incelemişlerdir. Zhang L. ve ark. (2017) ticari binalarda yer alan elektrikli araç otoparklarının şarj yönetimi problemini ele almışlardır. Her bir aracın şarj talebini gözönüne alarak toplam şarj maliyetini minimize etmeye çalışmışlardır. Ayrıca otoparktan ayrılırken aracın enerji seviyesi istenen seviyenin altında kaldığında araç sahibine ceza ödemesi yapılmıştır. Mohammadi ve ark. (2017) yük profilini iyileştirmek için elektrikli araç otoparkının enerji yönetim problemini ele almışlardır. Ayrıca problemin çözümünde gerilimdeki değişimleri, gerilim kararlılığını ve sistemdeki enerji kayıplarını da hesaba katmışlardır. Chen ve ark. (2017) elektrikli araç otoparklarında toplu olarak yer alan ve esnek bir yük olarak değerlendirilen elektrikli araçların elektrik piyasasına katılımını teşvik etmek için eVoucher adlı bir program önermişlerdir. Zare ve ark. (2018) elektrikli araç otoparklarının şarj gücü taleplerini dikkate alarak yeni bir dağıtım sistemi planı önermişlerdir. Önerilen yapı fiderlerin ve transformatör merkezlerinin yükünün azaltılmasına yardımcı olmaktadır. Fakat yukarıda bahsedilen çalışmalarda PV güç üretim sistemi ve batarya enerji depolama sisteminin olmadığının altı çizilmelidir. Mohammadi ve ark. (2013) 24 saatlik bir süre için toplam enerji kaybının azaltılması ve gerilim profilinin iyileştirilmesi için elektrikli araç otoparkı ve PV güç üretim sisteminin optimum yerinin belirlenmesi için bir model sunmuşlardır. Chukwu ve ark. (2014) şebekeye enerji satabilen PV tabanlı yenilenebilir enerji 


\section{Avrupa Bilim ve Teknoloji Dergisi}

kaynağına sahip bir otoparkın güç kapasitesini tahmin etmek için matematiksel bir model oluşturmuşlardır. Çalışmada şarj etmek amacıyla otoparka gelen araçların enerji yönetim problemini ele almışlardır. Rahmani-andebili (2016) PV güç üretim sistemine sahip elektrikli araç otoparklarının en uygun şekilde boyutlandırılması, yerleştirilmesi ve güç faktörü ayarının yapılması için bir model önermiştir. Yapılan çalışma ile toplam elektrik maliyeti azaltılmış ve sistemdeki tüm baraların gerilimi uygun seviyeye getirilmiştir. Nunes ve ark. (2016) PV güç üretim sistemine sahip otoparkların yaygınlığının artmasına engel olan teknik, çevresel ve finansal problemleri ele alan bir inceleme yapmışlardır. Mathur ve ark. (2018) PV güç üretim sistemine sahip bir elektrikli araç otoparkının pik fiyatlandırma döneminde şebekeden çektiği gücü minimize etmek amacıyla elektrikli araçların optimum şekilde yönetildiği bir algoritma önermişlerdir. PV güç üretim sistemi şebekeden çekilen gücün azaltılması ve elektrikli araç otopark sahibinin kârının arttırılması amacı ile kullanılmıştır. Alkan ve ark. (2018) PV güç üretim sistemi içeren bir elektrikli araç otoparkının çeşitli çalışma koşullarında dağıtım sistemine olan etkilerini analiz etmişlerdir. Zhang Y. ve ark. (2018) elektrikli araç otoparkı için kârı maksimize eden bir yapı önermişlerdir. Bu yapıda elektrikli araçlar ile ilgili veriler merkezi bir kontrolör tarafindan toplanmaktadır. Ayrıca PV güç üretim sistemi için öngörü değerleri de hesaba katılmıştır. Fakat Mohammadi ve ark. (2013), Chukwu ve ark. (2014), Rahmaniandebili (2016), Nunes ve ark. (2016), Mathur ve ark. (2018), Alkan ve ark. (2018), Zhang Y. ve ark. (2018) yapmış oldukları çalı̧̧malarda PV güç üretim sistemine yer vermelerine rağmen enerji depolama sistemine yer vermemişlerdir. Sarker ve ark. (2018) toplayıcının bir grup elektrikli araç otoparkını yönettiği ve gün öncesi piyasasına katıldığı bir yapıyı incelemişlerdir. Ayrıca toplam geliri artırmak için bir enerji depolama sistemi de değerlendirilmiştir. Fakat bu çalışmada PV güç üretim sistemi yer almamıştır.

\subsection{Katkılar ve Çalışma Organizasyonu}

$\mathrm{Bu}$ çalışmada PV-batarya hibrit sistemi içeren bir elektrikli araç otoparkının şarj yönetiminin karışık tamsayılı doğrusal programlama modeli önerilmiştir. Hibrit sistemin yer aldığı ve dinamik elektrik fiyatlarının uygulandığı çalışmada toplam şarj maliyetinin minimize edilmesi hedeflenmiştir. Bu çalışmanın katkıları şunlardır.

- Şebekeden daha az enerji kullanılması ve toplam elektrik maliyetinin düşürülmesi amacıyla PV-batarya hibrit sistemi çalışmaya dahil edilmiştir. PV sistem temiz ve ucuz olarak enerji temin edebilmektedir ve otoparktaki araçlara gölge sağlayabilmektedir. Ayrıca diğer çalışmalardan farklı olarak toplam kârın arttırılması amacıyla batarya enerji depolama sistemine de yer verilmiştir. Hem PV sistemde üretilen fazla enerji hem de şebeke elektrik fiyatının ucuz olduğu periyotlarda şebekeden satın alınan enerji, enerji depolama sisteminde depo edilmektedir.

- Araçların otoparka gelme zamanları ve geldikleri andaki enerji durumları hesaba katılmıştır. Ayrıca gerçek hayata uygunluğu açısından çalışmada 10 farklı elektrikli araç modeline yer verilmiştir.

Çalışmanın geri kalanı şu şekilde düzenlenmiștir. Önerilen matematiksel modelleme Bölüm 2'de açıklanmıştır. Daha sonra, Bölüm 3'te farklı durum çalışmaları gerçekleştirilmiştir ve ilgili sonuçların karşılaştırılması yapılmıştır. Son olarak, Bölüm 4 'te önemli sonuçlar vurgulanmıştır.

\section{Matematiksel Modelleme}

Bu çalışmada, PV ve batarya sisteminin yer aldığı bir elektrikli araç otoparkında elektrikli araçların şarjları yönetilerek şarj maliyetleri açısından optimum şarj durumlarının belirlendiği bir yapı önerilmiştir. Önerilen yapı Şekil 1'de verilmiştir. PV sistemin araçlara gölgelik yapacak şekilde yer aldığı düşünülmüştür. Batarya, PV sistemde üretilen fazla enerjinin veya şebeke elektrik fiyatının ucuz olduğu periyotlarda şebekeden satın alınan enerjinin depo edilmesi için kullanılmaktadır. PV ve batarya hibrit sistemi elde edilen kârın arttırılarak elektrik maliyetinin düşürülmesine yardımcı olmaktadır. Elektrikli araç sahipleri, elektrikli araç otoparkı içerisinde şarj maliyetlerini düşürebilme imkânına sahip olmaktadırlar.

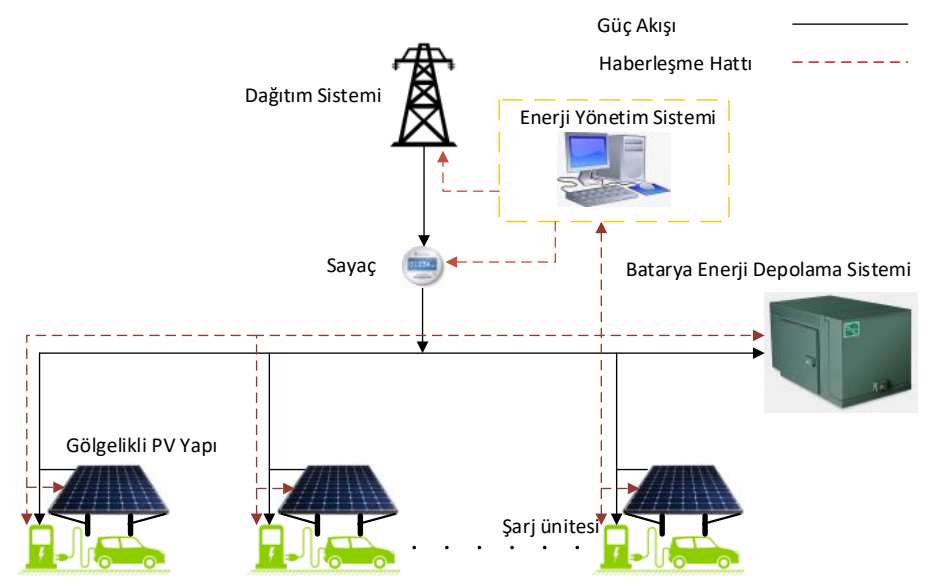

Şekil 1. PV ve batarya sisteminin yer aldığı elektrikli araç otopark yapısı

Çalışmanın amacı PV ve batarya sistemi içeren bir elektrikli araç otoparkındaki araçların toplam şarj maliyetinin minimize edilmesidir. Amaç fonksiyonu (1) numaralı ifadede verilmiştir. 
$\min \sum_{t}\left(P_{t}^{\text {grid }} \cdot \Delta T \cdot \lambda^{\text {price }}\right)$

(2) numaralı eşitlik güç dengesini ifade etmektedir. Burada şebekeden çekilen güç, enerji depolama sisteminin deşarj gücü ve PV sistemde üretilen gücün toplamının elektrikli araçların şarj güçlerinin toplamı ve enerji depolama sistemi şarj gücünün toplamına eşit olduğu belirtilmiştir.

$$
P_{t}^{g r i d}+P_{t}^{E S S_{-} d i s} \cdot D E^{E S S}+P_{t}^{P V}=P_{t}^{E S S_{-} c h}+\sum_{m} P_{t}^{E V_{-} c h}, \forall t
$$

Elektrikli araçların şarj güçlerinin sınırları (3) numaralı eşitsizlik ile ifade edilmiştir.

$$
P_{m, t}^{E V_{0} c h} \leq C R^{E V}, \forall m, \quad t \in\left[T_{m}^{a}, T_{m}^{d}\right]
$$

Elektrikli araçların $t$ anındaki enerji durumlarının ifadesi (4) numaralı eşitlikte yer almaktadır. $t$ anındaki enerji durumu $t-1$ anındaki enerji durumu ile eğer gerçekleşirse $t-1$ anından $t$ anına kadar şarj edilen enerjinin toplamınına eşittir.

$\operatorname{SoE}_{m, t}^{E V}=S o E_{m,(t-1)}^{E V}+C E_{m}^{E V} \cdot P_{m, t}^{E V_{c h}} \cdot \Delta T, \quad \forall m, t \in\left[T_{m}^{a}, T_{m}^{d}\right]$

Elektrikli araçlar için izin verilen maksimum enerji durumlarının ifadesi ise (5) numaralı eşitsizlikte yer almaktadır.

$S o E_{m, t}^{E V} \leq S o E_{m}^{E V, m a x}, \quad \forall m, \forall t$

(6) numaralı eşitlikte elektrikli araçların otoparka geldikleri andaki enerji durumlarının ifadesi yer almaktadır.

$S o E_{m, t}^{E V}=S o E_{m}^{E V, i n i}, \quad \forall m, t=T_{m}^{d}$

Elektrikli araçların otoparkta yer almadıkları zamanlarda şarj olmaması durumu için ise aşağıdaki (7) numaralı eşitliğe yer verilmiştir.

$P_{m, t}^{E V_{-} c h}=0, \quad \forall m, t \notin\left[T_{m}^{a}, T_{m}^{d}\right]$

(8) ve (9) numaralı ifadelerde enerji depolama sisteminin sırasıyla şarj ve deşarj gücü sınırları yer almaktadır.

$P_{t}^{E S S_{-} c h} \leq C R^{E S S} \cdot u_{t}^{E S S}, \forall t$

$P_{t}^{E S S_{-} \text {dis }} \leq D R^{E S S} \cdot\left(1-u_{t}^{E S S}\right), \forall t$

Enerji depolama sisteminin $t$ anındaki enerji durumunun ifadesi (10) numaralı eşitlikte yer almaktadır. Burada $t$ anındaki enerji durumu bir önceki enerji durumu ile şarj/deşarj edilen enerjinin toplanması/çıkarılması ile elde edilmektedir.

$S o E_{t}^{E S S}=S_{0} E_{(t-1)}^{E S S}+C E^{E S S} \cdot P_{m, t}^{E S S_{-} c h} \cdot \Delta T-P_{m, t}^{E S S \text { dis }} \cdot \Delta T, \quad \forall t$

(11), (12), (13) numaralı ifadelerde ise enerji depolama sisteminin sırasıyla başlangıçtaki enerji durumu, izin verilen maksimum ve minimum enerji düzeyi yer almaktadır.

$$
\begin{aligned}
& \operatorname{SoE}_{t}^{E S S}=S o E^{E S S, i n i}, \quad t=1 \\
& S o E_{t}^{E S S} \leq S o E^{E S S, \max }, \quad \forall t \\
& \operatorname{SoE}_{t}^{E S S} \geq S o E^{E S S, \min }, \quad \forall t
\end{aligned}
$$

\section{Test ve Sonuçlar}

\subsection{Giriş Verileri}

Otoparkta her biri farklı karakteristiklere sahip 10 araçtan her birinden 10 adet olmak üzere toplamda 100 araç yer almaktadır. Her aracın elektrikli araç otoparkına gelme zamanları ve geldikleri anda bataryalarındaki enerji durumları farklı olarak belirlenmiştir. Araç sahiplerinin otoparktan ayrılırken tam şarj durumu ile ayrılmak istedikleri ve araçların tam şarj olması için 1469,63 kWh enerji ihtiyacının olduğu varsayılmıştır. Otoparkta bir batarya enerji depolama sistemi ve PV güç üretim sistemi yer almaktadır. Otoparkta yer alan 10 farklı elektrikli araca ait özellikler Tablo I.'de verilmiştir. Önerilen çalışma GAMS v.24.1.3'da test edilmiştir. Problemin çözümü için ticari çözücü CPLEX v.12 kullanılmıştır. 
Tablo 1. Elektrikli Araçların Karakteristikleri

\begin{tabular}{lcc}
\hline Elektrikli Araç Tipleri & $\begin{array}{c}\text { Batarya } \\
\text { Kapasitesi } \\
{[\mathrm{kWh}]}\end{array}$ & $\begin{array}{c}\text { Şarj Gücü } \\
{[\mathrm{kW}]}\end{array}$ \\
\hline Volkswagen E-Golf [Volkswagen] & 36 & 7.2 \\
BMW i-3 [BMW] & 33 & 7.7 \\
Mercedes B-Class [Mercedes] & 28 & 10 \\
Tesla Model-S [Tesla] & 100 & 10 \\
Fiat 500E [Fiat] & 24 & 6.6 \\
Ford Focus Electric [Ford] & 23 & 6.6 \\
Kia Soul EV [Kia] & 27 & 6.6 \\
Mitsubishi i-MiEV [Mitsubishi] & 16 & 3.6 \\
Chevy Volt [Chevy] & 18 & 3.6 \\
Nissan LEAF [Nissan] & 40 & 6.6 \\
\hline \hline
\end{tabular}

Elektrikli araç otoparkında yer alan $100 \mathrm{~kW}$ ’lı PV güç üretim sisteminin yaz aylarını kapsayan günlük ortalama enerji üretim eğrisi Şekil 2'de verilmiştir. Güç üretiminin 07:00 ile 18:00 saatleri arasında gerçekleştiği belirtilmelidir.

Elektrikli araç otoparkı için şebekeden enerji satın alımlarında uygulanan birim elektrik fiyat tarifesi Şekil 3 'te saatlik olarak verilmiştir. 17:00-18:00 aralığında enerji birim fiyatının en yüksek seviyede olduğu görülmektedir.

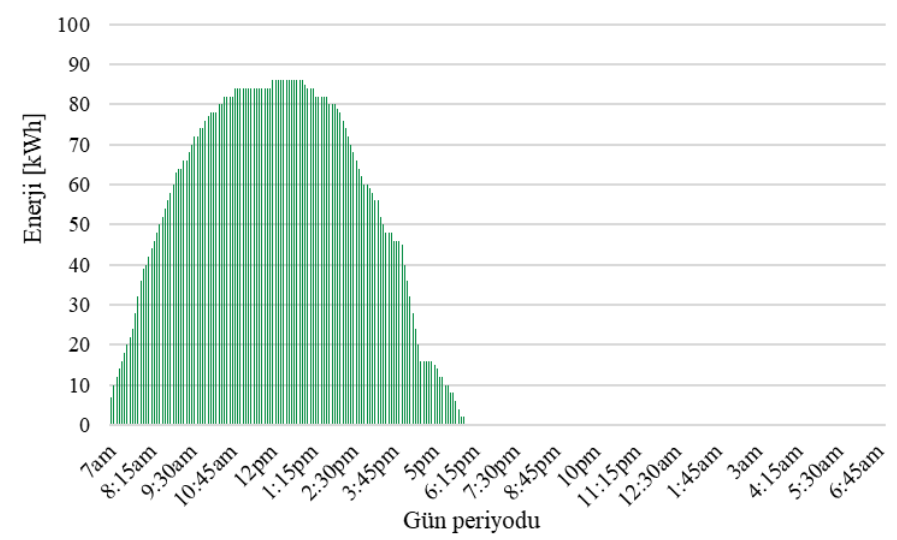

Şekil 2. 100 kW'lık PV sisteme ait enerji üretimi

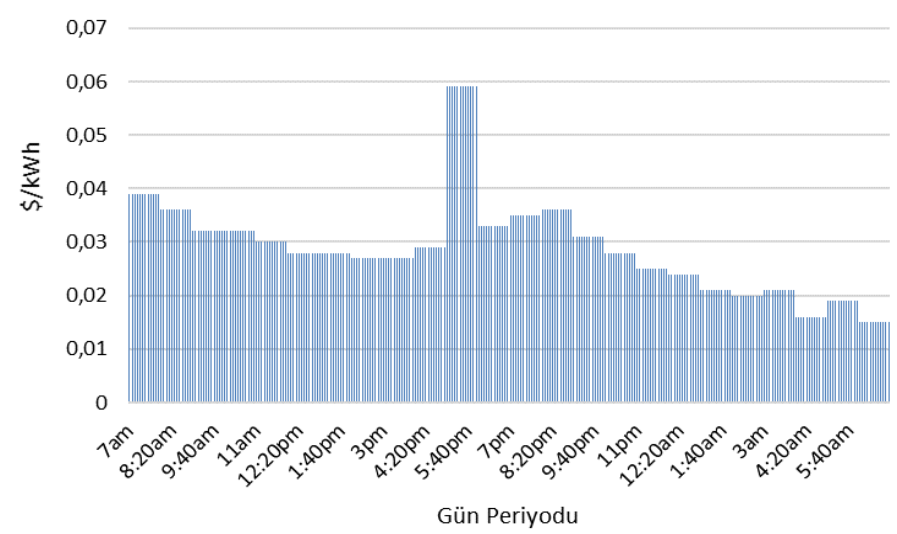

Şekil 3. Saatlik elektrik birim fiyatları

\subsection{Simulasyon ve Karşılaştırmalar}

Önerilen yapıyı kanıtlamak için aşağıda verilen durum çalışmaları yapılmıştır.

- Temel Durum: Enerji depolama sistemi ve PV sistem yer almamaktadır.

- Durum 1: $50 \mathrm{kWh}$ 'lik batarya enerji depolama sistemi ve $50 \mathrm{~kW}$ 'llk PV sistem yer almaktadır.

- Durum 2: $100 \mathrm{kWh}$ 'lik batarya enerji depolama sistemi ve $50 \mathrm{~kW}$ 'lık PV sistem yer almaktadır.

- Durum 3: $50 \mathrm{~kW}$ 'lik PV sistem yer alıp enerji depolama sistemi yer almamaktadır.

- Durum 4: $50 \mathrm{kWh}$ 'lik batarya enerji depolama sistemi ve $100 \mathrm{~kW}$ 'lık PV sistem yer almaktadır.

- Durum 5: $100 \mathrm{kWh}$ 'lik batarya enerji depolama sistemi ve $100 \mathrm{~kW}$ 'lık PV sistem yer almaktadır. 
- Durum 6: $100 \mathrm{~kW}$ 'lik PV sistem yer alıp enerji depolama sistemi yer almamaktadır.

Çalışmadan elde edilen sonuçlar Tablo 2'de verilmiştir. Elde edilen sonuçlara göre toplam enerji maliyetinin en çok durum 5 'te azaldığı görülmüştür. PV güç üretim sisteminin kapasitesinin arttırılması ile enerji maliyetinin önemli derecede azaltılabildiği görülmüştür. Fakat Durum 1 ve Durum 2 ile Durum 4 ve Durum 5'te aynı özellikteki PV sistem içeren yapıya yerleştirilen farklı boyutlardaki enerji depolama sistemleri ile enerji maliyetinde önemli derecede bir azalma meydana gelmediği görülmektedir. PV sistemin yer alıp enerji depolama sisteminin yer almadığı Durum 3'ün Durum 1 ve Durum 2 ile, Durum 6'nın Durum 4 ve Durum 5 ile karşılaştırması yapıldığında enerji depolama sisteminin toplam elektrik maliyetini önemli derecede azaltmadığı sonucuna varılabilir. En kötü durum ise toplam elektrik maliyetinin 45,71 \$ olduğu temel durumdur. En iyi durumda en kötü durum olan temel duruma göre 19,36 \$ tasarruf elde edilmiştir. Bu çalışmadan elde edilen sonuçlara göre elektrikli araç otoparkları için özellikle PV sistemlerin dahil edilmesi ile toplam şarj maliyetlerinde önemli bir azalma sağlanabileceği görülmektedir.

Tablo 2. Durum Çalışmaları Sonuçları

\begin{tabular}{lccc}
\hline \hline $\begin{array}{l}\text { Durum } \\
\text { Çalı̧maları }\end{array}$ & $\begin{array}{c}\text { Batarya } \\
\text { Kapasitesi } \\
{[\mathrm{kWh}]}\end{array}$ & $\begin{array}{c}\text { PV Sistem } \\
{[\mathrm{kW} / \mathrm{kWh}]}\end{array}$ & $\begin{array}{c}\text { Toplam } \\
\text { Elektrik } \\
\text { Maliyeti } \\
{[\$]}\end{array}$ \\
\hline Temel Durum & - & - & 45,71 \\
Durum 1 & 50 & $50 \mathrm{~kW} / 312,54 \mathrm{kWh}$ & 35,53 \\
Durum 2 & 100 & $50 \mathrm{~kW} / 312,54 \mathrm{kWh}$ & 35,37 \\
Durum 3 & - & $50 \mathrm{~kW} / 312,54 \mathrm{kWh}$ & 36,31 \\
Durum 4 & 50 & $100 \mathrm{~kW} / 625,08 \mathrm{kWh}$ & 26,52 \\
Durum 5 & 100 & $100 \mathrm{~kW} / 625,08 \mathrm{kWh}$ & 26,35 \\
Durum 6 & - & $100 \mathrm{~kW} / 625,08 \mathrm{kWh}$ & 27,30 \\
\hline
\end{tabular}

Şekil 4’te Temel Durum, Durum 1 ve Durum 2 için şebekeden çekilen güçlerin karşılaştırması yapılmıştır. Şebekeden en fazla güç Temel Durumda çekilmektedir. Durum 1 ve Durum 2'de 50 kW'lık PV sistem yer almaktadır. Enerji depolama sisteminin yer aldığı Durum 1 ve Durum 2'de ise şebekeden çekilen güçler azalmıştır.

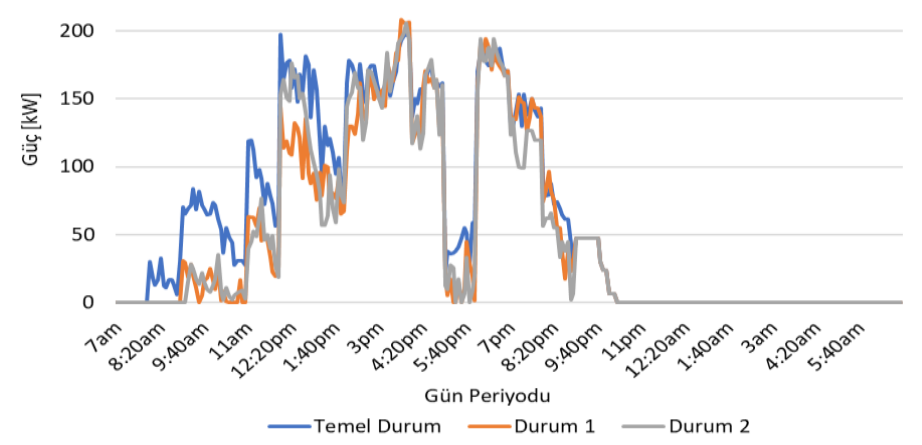

Şekil 4. Temel Durum, Durum 1 ve Durum 2'de şebekeden çekilen güç

Temel Durum ile Durum 5'te șebekeden çekilen güçlerin karşılaştırması Şekil 5'te verilmiştir. PV güç üretiminin olduğu Durum 5’te saat 12:00'a kadar şebekeden hiç güç çekilmediği görülmektedir. Ayrıca PV güç üretim sisteminin yer alması ile şebekeden çekilen toplam enerjinin azaldığı ifade edilebilir.

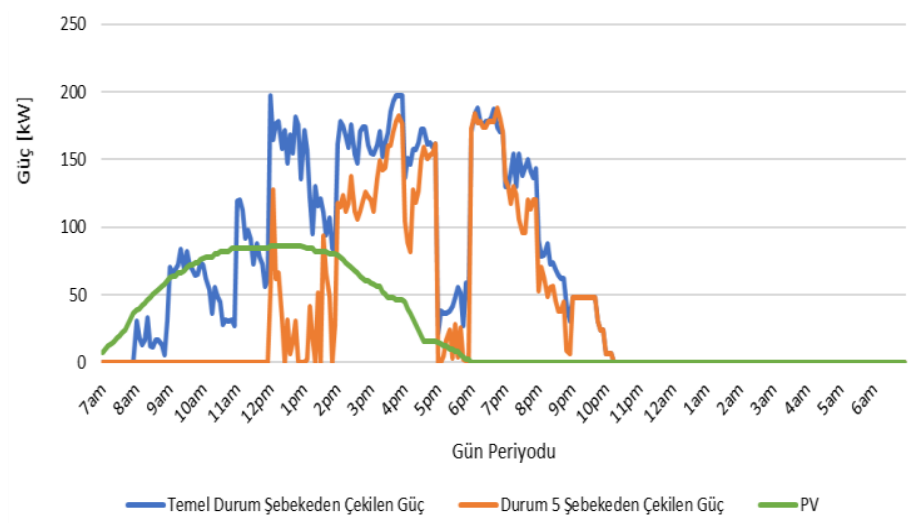

Şekil 5. Temel Durum ve Durum 5'te şebekeden çekilen güçler ve Durum 5'te $100 \mathrm{~kW}$ 'lık PV sistemde üretilen güç 
Durum 5'te bataryanın enerji durumunun değişimi Şekil 6'da verilmiştir. Özellikle elektrik birim fiyatının en yüksek olduğu 18:00'dan önce bataryanın tam şarj olduğu görülmektedir. Ayrıca bu periyodun elektrik birim fiyatı açısından en ekonomik periyot olduğu ifade edilebilir.

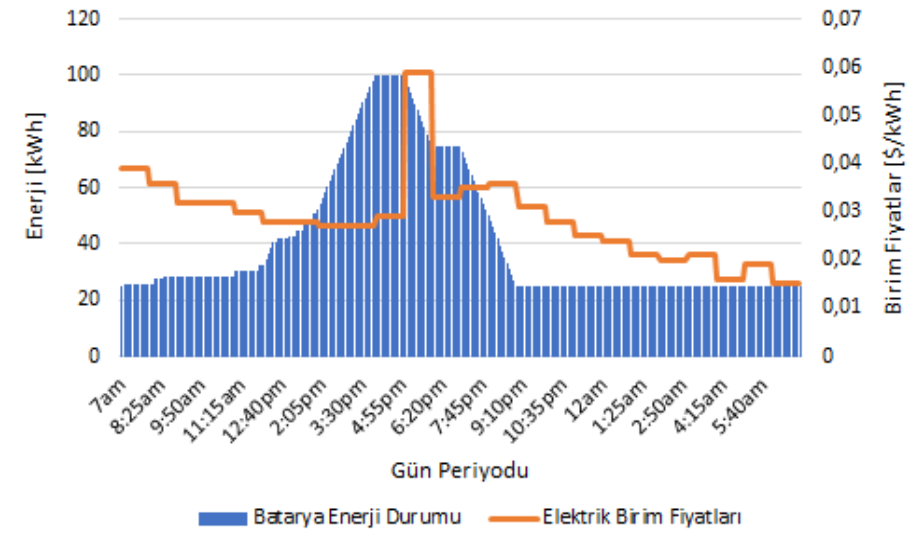

Şekil 6. Durum 5'te bataryanın enerji durumu ve saatlik elektrik birim fiyatları

Wolkswagen 4 (WO4) ve Mitsubishi 10 (MIT10) elektrikli araçlarının elektrikli araç otoparkında oldukları periyot içerisinde enerji durumlarının ifadesi Şekil 7'de verilmiş̧ir. Elektrikli araçlar otoparktan ayrıldıkları anda tam şarj olmuş durumdadırlar. Şarj maliyetini düşürmek için elektrikli araçların geldikleri anda şarj olmadıkları, elektrik fiyatının düşük olduğu periyotlarda şarj oldukları görülmektedir.

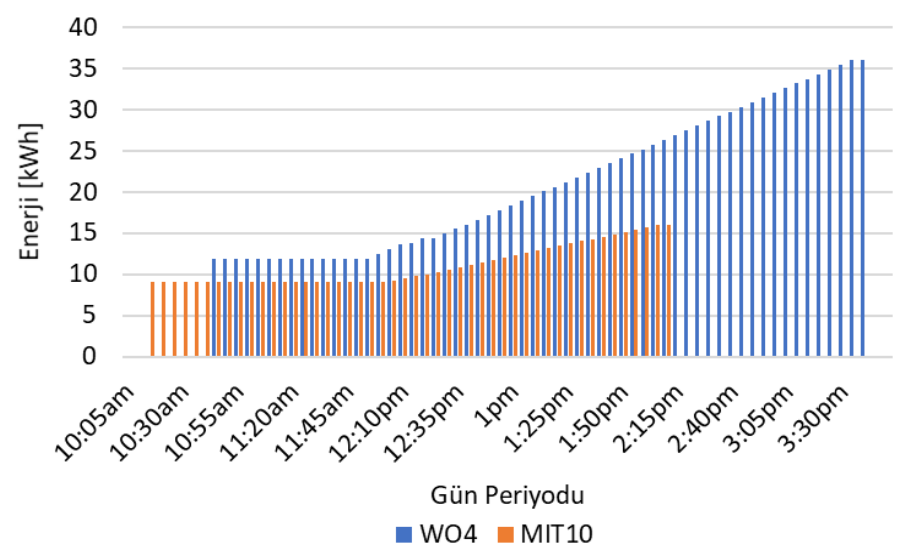

Şekil 7. WO4 ve MIT10 elektrikli aracının enerji durumu

\section{Sonuç}

Elektrikli araç sayısı her geçen gün giderek artmaktadır. Artan bu sayı düşünüldüğünde şarj konusunda elektrik şebekesinde aşırı yüklenme gibi birçok problem yaşanabilir. Bu açıdan elektrikli araçların şarj yönetimi stratejisi oldukça önemli bir konu haline gelmiştir. Elektrik piyasalarına katılabilen elektrikli araç otoparkları, elektrikli araç sahiplerine araçlarını daha ekonomik bir şekilde şarj edebilmek için iyi bir firsat sunmaktadır. Çünkü bir elektrikli araç nispeten küçük enerji kapasitesi ile elektrik piyasalarına katılamayacağından dolayı fiyat alan konumdadır ve dolayısıyla tek başına şarj maliyetini düşürememektedir. Elektrikli araç otoparkında kullanılan PV-batarya hibrit sistem şarj maliyetinin düşürülmesine yardımcı olabilmektedir. Enerjinin ucuz olarak temin edilebildiği PV sistem çevre kirliliğinin azaltılması konusunda önemli bir avantaj sağlarken, batarya enerji depolama sistemi de PV sistemde üretilen fazla enerjinin ve şebeke elektrik fiyatının ucuz olduğu periyotlarda şebekeden satın alınan enerjinin depolanmasını sağlayabilmektedir. Bataryada depolanan enerji, PV üretiminin olmadığı ve şebeke elektrik fiyatının yüksek olduğu periyotlarda sisteme enjekte edilebilmektedir.

$\mathrm{Bu}$ çalışmada PV-batarya hibrit sistemi içeren bir elektrikli araç otoparkının toplam elektrik maliyetinin minimize edilmesi amacıyla bir şarj yönetimi modeli oluşturulmuştur. Yapılan durum çalışmalarından elde edilen sonuçlara göre PV-batarya hibrit sisteminin toplam elektrik maliyetini düşürdüğü görülmüştür. Elde edilen sonuçlar arasında dikkat çeken bir diğer durum da PV üretiminin olduğu bazı periyotlarda şebekeden hiç güç çekilmemesi olmuştur. Genel olarak PV sistemin toplam elektrik maliyetinin azaltılması açısından önemli bir katkısının olduğu sonucuna varılabilirken, batarya enerji depolama sisteminin ise sistem sonuçları üzerinde büyük bir etkisinin olmadığı sonucuna varılabilir.

PV-batarya hibrit sistemi içeren elektrikli araç otoparkının bir toplayıcı aracılığı ile enerji piyasalarına katılımı (gün öncesi piyasası, dengeleme piyasası) ve şebekeye elektrik satması gelecek çalışmalarda ele alınabilir. 


\section{Kaynakça}

Alkan B., Uzun, B., Erenoğlu, A.K., Erdinç, O., Turan, M.T., Catalão, J.P.S. 2018. Scenario Based Analysis of an EV Parking Lot Equipped with Roof Top PV Unit within Distribution Systems. IEEE International Conference on Smart Energy Systems and Technologies, 10-12 Sept., 2018, Seville, Spain.

Amini, M. H., Boroojeni K. G., Wang, C. J., Nejadpak, A., Iyengar, S. S., Karabasoğlu, O. 2016. Effect of Electric Vehicle Parking Lots' Charcing Demand As Dispatchable Loads on Power Systems Loss. 2016 IEEE International Conference on Electro Information Technology (EIT), 19-21 May, 2016, Grand Forks, ND, USA.

BMW, i3 Specifications, http://www.plugincars.com/bmw-i3.html.

Chevy, Volt Specifications, http://www.plugincars.com/chevrolet -volt.

Chen, T., Pourbabak, H., Liang, Z., Su, W., Yu, P. 2017. Participation of Electric Vehicle Parking Lots into Retail Electricity Market with eVoucher Mechanism. 2017 IEEE Transportation Electrification Conference and Expo, Asia-Pacific (ITEC Asia-Pacific), 710 Aug, 2017, Harbin, China.

Chukwu, U. C., Mahajan, S. M. 2014. V2G Parking Lot With PV Rooftop for Capacity Enhancement of a Distribution System. IEEE Transactions on Sustainable Energy 5(1), 119-127.

Fiat, 500E Specifications, http://www.plugincars.com/fiat-500e.

Ford, Focus Electric Specifications, http://www.plugincars.com/ ford -focus-electric.

International Energy Agency (IEA), Global EV Outlook 2018, Towards cross-modal electrification, Tech. Rep., 2018. https://webstore.iea.org/download/direct/1045?fileName=Global_EV_Outlook_2018.pdf.

Kia, Soul Specifications, http://www.plugincars.com/kia-soul-ev.

Jozi, F., Mazlumi, K., Hosseini, H. 2017. Charging and Discharging Coordination of Electric Vehicles in a Parking Lot Considering The Limitation of Power Exchange With the Distribution System. 2017 IEEE 4th International Conference on Knowledge-Based Engineering and Innovation (KBEI), 22 Dec, 2017, Tehran, Iran.

Mathur, A. K., S, C.T., Yemula, P. K. 2018. Optimal Chargng Schedule for Electric Vehicles in Parking Lot with Solar Power Generation. 2018 IEEE Innovative Smart Grid Technologies - Asia (ISGT Asia), 22-25 May, 2018, Singapore, Singapore.

Mercedes, B-Class Specifications, http://www.plugincars.com/ mercedes-b-class-e-cell.

Mitsubishi, i-MiEV Specifications, ex.php?q=aHR0cHM6Ly9lbi53aWtpcGVkaWEub3JnL3dpa2kvTW10c3ViaXNoaV9pLU1pRVY.

Mohammadi, E., Foroughi, A., Rashidinejad M., Fadaeinedjad, R., Moschopoulos, G. 2013. Optimal Allocation of Parking Lots and PV Systems in Distribution System for Energy Loss Reduction and Voltage Profile Improvement. 2013 26th IEEE Canadian Conference of Electrical and Computer Engineering (CCECE), 5-8 May, 2013, Regina ,SK, Canada.

Mohammadi, E., Fadaeinedjad, R., Rashidinejad, M., Mahdavinia, A. 2017. Optimal Placement and Charge/Discharge Scheduling of Electric Parking Lots Considering Reactive Power Generation Capability. 2017 Smart Grid Conference (SGC), 20-21 Dec, 2017, Tehran, Iran.

Neyestani, N., Damavandi, M. Y., Shafie-khah, M., Catalão J. P. S., Contreras, J. 2015. PEV Parking Lot Behavior Equilibria in Energy and Reserve Markets. 2015 IEEE Power \& Energy Society General Meeting (PES GM), 26-30 July, 2015, Denver, CO, USA.

Nissan, Leaf Specifications, http://www.plugincars.com/nissan-leaf.

Nunes, P., Figueiredo, R., Brito, M. C., 2016. The Use of Parking Lots to Solar-Charge Electric Vehicles. Renewable and Sustainable Energy Reviews 66, 679-693.

Rahmani-andebili, M. 2016. Optimal Power Factor for Optimally Located and Sized Solar Parking Lots Applying Quantum Anneling. IET Generation, Transmission \& Distribution 10(10), 2538-2547.

Sarker, M. R., Pandžić, H., Sun, K., Ortega-Vazquez, M. A. 2018. Optimal Operation of Aggregated Electric Vehicle Charging Stations Coupled with Energy Storage. IET Generation, Transmission \& Distribution 12(5), 1127-1136.

Shafie-khah, M., Heydarian-Forushani, E., Osório, G. J., Gil, F. A. S., Aghaei, J. 2016. Optimal Behavior of Electric Vehicle Parking Lots as Demand Response Aggregation Agents. IEEE Transactions on Smart Grid 7(6), 2654-2665.

Tesla, Model S Specifications, http://www.plugincars.com/tesla-model-s.

Tie, S. F., Tan, C. W. 2012. A Review of Energy Sources and Energy Management System in Electric Vehicles. Renewable and Sustainable Energy Reviews 20, 82-102.

Volkswagen, E-Golf Specifications, http://www.plugincars.com/ volkswagen-electric-e-golf-blue-e-motion.

Zhang, L., Li, Y. 2017. Optimal Management for Parking-Lot Electric Vehicle Charging by Two-Stage Approximate Dynamic Programming. IEEE Transactions on Smart Grid 8(4), 1722-1730.

Zhang, P., Shao, W., Qu, H., Xu, W., Xu, Z. 2016. Study on Charging Strategy of Electric Vehicle Parking Lot Based on İmproved PSO. 2016 Chinese Control and Decision Conference (CCDC), 28-30 May, 2016, Yinchuan, China.

Zhang, Y., Cai, L. 2018. Dynamic Charging Scheduling for EV Parking Lots With Photovoltaic Power System. IEEE Access 6, 56995-57005. 